\title{
Depth profile investigations of surface modifications of limestone artifacts by laser-induced breakdown spectroscopy
}

\author{
Giorgio S. Senesi ${ }^{1}$ (1) Gustavo Nicolodelli ${ }^{2}$ - Debora M. B. P. Milori ${ }^{2}$ • \\ Olga De Pascale ${ }^{1}$
}

Received: 1 March 2017/ Accepted: 14 August 2017/Published online: 20 August 2017

(C) Springer-Verlag GmbH Germany 2017

\begin{abstract}
The study of the degradation mechanisms of materials constituting historical buildings is very relevant in the context of cultural heritage preservation. In this work, a limestone sample collected from the masonry blocks of the entrance gate of historic Castello Svevo, Bari, Italy, was subjected to depth profile elemental analysis of the ablated black crust and the underlying limestone by double pulse laser-induced breakdown spectroscopy. The specific elemental components were identified and their concentrations along the sample profile analyzed, so allowing to identify the boundary between the weathered and unaltered rock. The laser-induced plasma stability, i.e., the absence of parameter changes during ablation, was verified to be constant and not to affect the elemental peak sizes during the entire depth analysis process when the plasma is confined in the ablation crater.
\end{abstract}

Keywords Cultural heritage $\cdot$ Limestone $\cdot$ Black crust $\cdot$ DP LIBS · Depth profile analysis

Electronic supplementary material The online version of this article (doi:10.1007/s12665-017-6910-4) contains supplementary material, which is available to authorized users.

Giorgio S. Senesi

giorgio.senesi@nanotec.cnr.it

1 CNR-Istituto di Nanotecnologia (NANOTEC) - PLasMI Lab, Via Amendola 122/D, 70126 Bari, Italy

2 Embrapa Instrumentation, Rua XV de Novembro 1452, São Carlos, SP 13560-970, Brazil

\section{Introduction}

The formation of inhomogeneous overlapping layers originated from the building techniques used and/or deterioration events occurred later, including the formation of black crusts, solid concretions and corrosion layers, the application of paint coats and overpaintings, and others, is typical of artifacts of cultural interest that have been exposed to anthropic and environmental factors. The study of both the microstructural and compositional depth profile of these accidental and/or intentional stratifications and of the stone layers underneath the original surface is crucial to develop appropriate strategies and practices for the conservation of monuments. In particular, the evaluation of sample stratigraphy before and after the removal of deteriorated layers is very relevant for performing any cleaning treatment (Siano et al. 2012). Further, depth profiling is very important for studying the art techniques used and performing authentication as, for example, in the case of ancient copper alloy artifacts and unglazed earthenware samples from archaeological excavations (Siano et al. 2009, 2011; Osticioli et al. 2012; Agresti and Siano 2014).

Traditionally, optical microscopy and scanning electron microscopy associated with energy-dispersive X-ray spectrometry (SEM-EDS) have been applied to evaluate the stratigraphy of cross-sections of small samples taken from an artifact. However, in many instances sample collection is not permitted, or, if permitted, samples are collected causing the minimum invasiveness, thus sometimes not in the most representative zones.

Laser-induced breakdown spectroscopy (LIBS) (Cremers and Radziemski 2006; Miziolek et al. 2006; Noll 2012) is an advanced analytical technique that allows to measure the content of a given analyte as a function of the number of laser pulses released to the target. Each laser 
pulse ablates a certain amount of material, first by removing dust coatings and then penetrating step by step into the sample underneath. The spectra of the successive laser pulses are processed to obtain the elemental distribution with depth, so providing accurate depth profiles through the various layers. LIBS has been recently used successfully (Kiros et al. 2013; Anglos and Detalle 2014; Senesi 2014; Lanza et al. 2015) to perform chemical depth profiling in order to identify and analyze rock surface alteration features, which allowed detailed investigation of rock varnish features as well as analysis of underlying pristine rock composition.

LIBS is considered a microdestructive technique (typical ablation diameter, 100-200 $\mu \mathrm{m}$ ) that features negligible invasiveness in most applications, including cultural heritage studies (Anglos and Detalle 2014). LIBS is faster and more accurate than other elemental analytical techniques such as X-ray methods (such as X-ray fluorescence, XRF), which cannot be performed with control of depth penetration, and SEM, secondary ion mass spectroscopy, X-ray photoelectron spectroscopy and nuclear particle irradiation, which can penetrate only a few $\mu \mathrm{m}$ below the surface. Further, the only two analytical techniques, i.e., ion beam analysis (IBA) and LIBS, that allow to gain information on the elemental profiles in the proximity of the surface feature a measurement range of several tens of $\mu \mathrm{m}$ (IBA) and up to several hundreds of $\mu \mathrm{m}$ (LIBS), respectively (Siano et al. 2011). In particular, LIBS capability in depth profile analysis appears relevant for the determination of compositional variations in proximity of sample surface, such as in the case of weathered artifacts in cultural heritage conservation (Maravelaki-Kalaitzaki et al. 2001; Siano et al. 2012), which often requires relatively deep analytical profiling as it was shown, for example, in the authentication of copper alloy and ceramic artifacts (Siano et al. 2009; Osticioli et al. 2012).

In the past, limestones were one of the most widely used building materials for many monuments. Limestones have generally homogeneous chemical characteristics being dominated by $\mathrm{CaCO}_{3}$, whereas physical properties such as hardness, fossil content and porosity may be highly variable (Smith et al. 2010). In particular, physical characteristics, especially porosity (Figueiredo et al. 2010), are mainly responsible for the durability of limestones exposed to aggressive environmental conditions (Beck and AlMukhtar 2010) that cause predominantly a gradual dissolution similarly to karstic erosion of natural limestone outcrops (Smith et al. 2010).

In a previous work (Senesi et al. 2016), the laser cleaning method has been applied successfully to remove the black crust from the surface, and single pulse (SP) and double pulse (DP) LIBS to evaluate the elemental composition of the entire profile by accumulating 28 shots on each sample position. In this work, a weathered limestone sample collected from the same masonry block of the left jamb of the southern entrance gate to the courtyard of Castello Svevo, Bari, Italy, was impinged with up to 110 successive laser pulses on the spot in three different areas
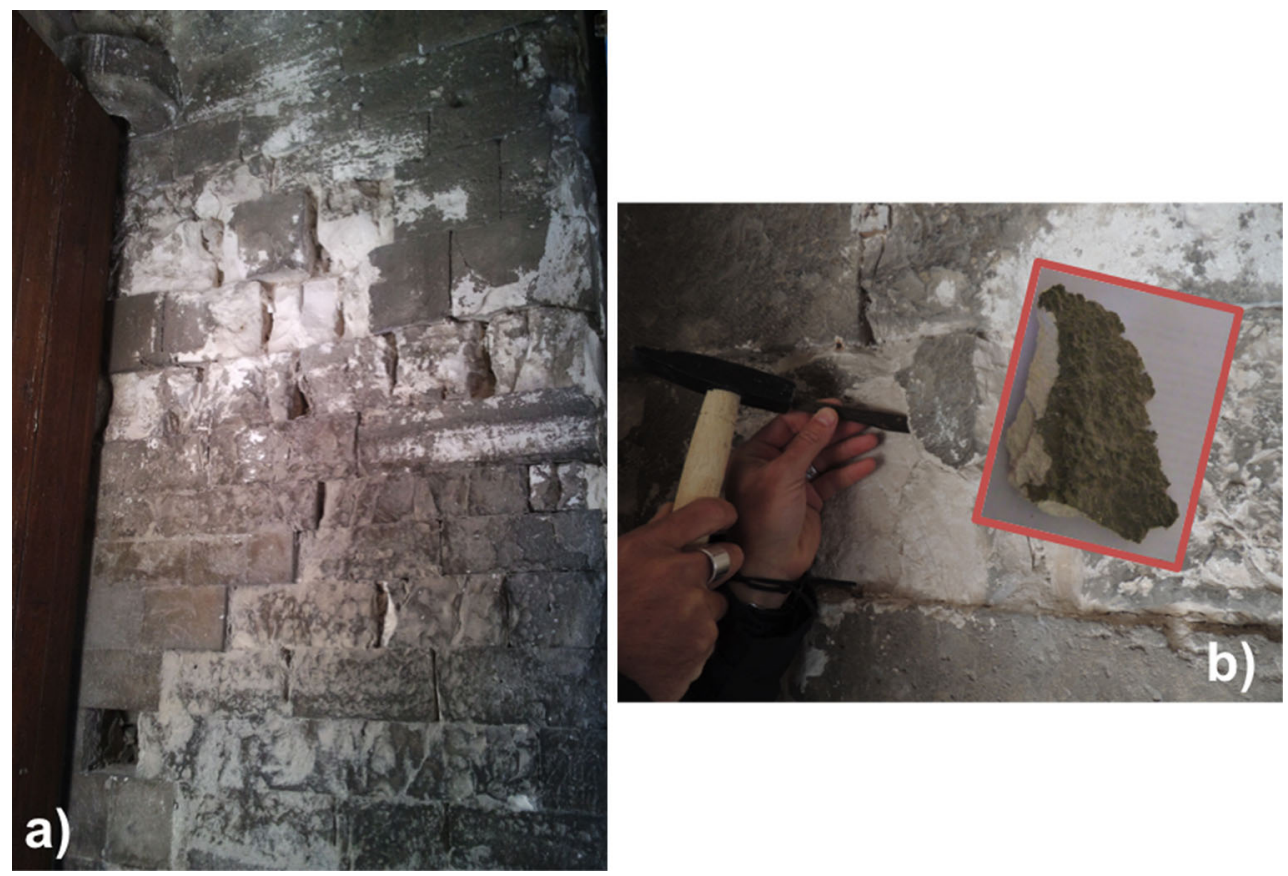

Fig. 1 Masonry limestone blocks of the jamb of the entrance gate of Castello Svevo (a) and area sampled (b). The red box inset shows the sample considered for this study 
(black crust and two areas laser cleaned, respectively) to track rapidly the in-depth profiling of the elements $\mathrm{Ca}, \mathrm{Fe}$, $\mathrm{Mg}, \mathrm{Mn}, \mathrm{Na}$ and $\mathrm{Sr}$ by DP LIBS using different laser wavelengths. This was done with the aim of identifying the boundary between the weathered and unaltered rock. Further, plasma stability was checked to ensure that changes measured in LIBS signal intensities with depth were due to a real change of the elemental concentrations in the sample, and not to changes in ablation parameters.

\section{Materials}

The sample was collected from a selected block of the limestone masonry of Castello Svevo, Bari, Italy (Fig. 1), which is an historic multilayered monument built originally by Roger the Norman in 1131 on the remains of a Byzantine structure. The material sampled showed the occurrence of surface degradation featuring a layer of black crust.

Since its origin, the castle has been restored many times during the years due also to its different uses (i.e., fortress, prison, etc.), thus it is difficult to determine the exact origin of the rocks used for its construction and evolution. Very probably, most rocks were quarried from the Cretaceous limestone deposits forming the framework of Apulia, which consists of a carbonate succession of about $3000 \mathrm{~m}$ thickness. This succession is divided in two formational units, the "Calcare di Bari" and the "Calcare di Altamura," separated by a transgression surface. Most probably, the rocks used to build the castle belong to the "Calcare di Bari" unit, which represents the lower and middle part of the succession outcropping in the northwestern Murgian area, and is referred to the ValanginianLower Turonian age (Dell'Anna and Laviano 1990). This unit is characterized by an irregular sequence of limestone, dolomitic limestone and dolomite that originated in a

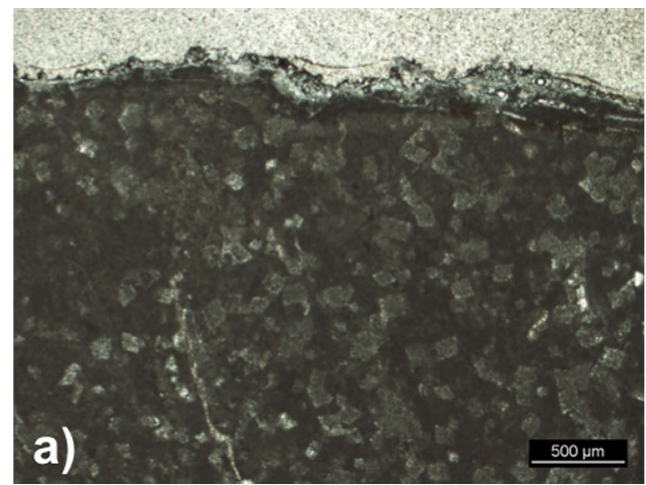

Fig. 2 OM images of the limestone sample analyzed. Details of the lozenge-shaped dolomite crystals replaced by pseudomorphic microcrystalline calcite (a). Details of the black crusts consisting of a fine depositional environment of the inner platform zone. Micrite, biomicrite, sparite, dolomicrite and calcarenite are the litho-facies most frequently found. In particular, micrite and sparite were the most used in buildings and monuments.

Chemically, the "Calcare di Bari" is composed of an acid soluble portion represented by $\mathrm{CaCO}_{3}, \mathrm{MgCO}_{3}$ and small amounts of other oxides, and an acid insoluble portion. From a mineralogical point of view, the $\mathrm{CaCO}_{3}$ consists of non-stoichiometric calcite containing $\mathrm{Mg}^{2+}$ as the main structural isomorphous element of $\mathrm{Ca}^{2+}$. This is shown by the shifting of the (104) reflection and the negative correlation existing between the $\mathrm{Mg}$-contents and the lattice parameters of calcite $(p=99 \%)$ (Dell'Anna and Laviano 1990). Dolomite results absent, while aragonite is present in trace amounts. The main minerals of the acid insoluble matter are poorly crystallized $\mathrm{Fe}$ and $\mathrm{Al}$ hydroxides and kaolinite associated with low amounts of illite, quartz, feldspars, micas and glauconite, and very small amounts of pyroxenes, tourmaline, zircon, chlorite, rutile and garnets (Dell'Anna and Laviano 1990).

\section{Methods}

A DP LIBS system consisting of two lasers operating at different wavelengths, i.e., $1064 \mathrm{~nm}$ (IR) and $532 \mathrm{~nm}$ (VIS) was used to perform the depth profiling analysis. The IR pulse was generated by a Nd:YAG Q-switch Ultra (Quantel) at a maximum energy of $75 \mathrm{~mJ}$ and a width of 6 ns. The VIS pulse was generated by a Nd:YAG Q-switch Brillant (Quantel) coupled with a second harmonic generator module at a maximum energy of $180 \mathrm{~mJ}$ and a width of 4 ns. A LTB-Aryelle 400 system was used to detect and select the wavelengths.

The in-depth profile study was performed by using a double pulse (DP) LIBS by accumulating 110 shots on

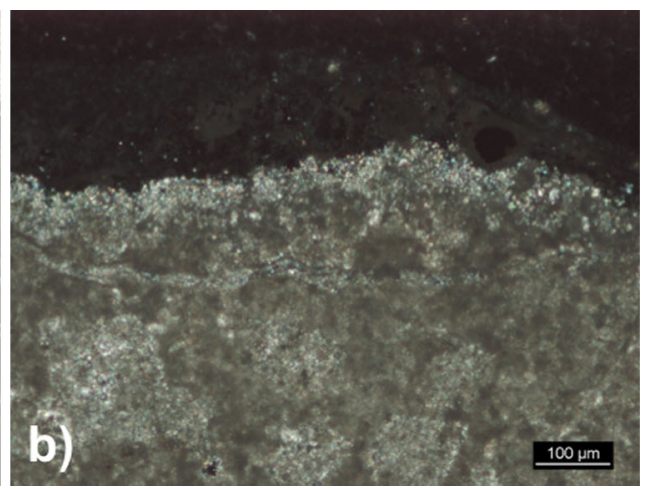

and opaque particulate component combined with quartz silt and bound by cryptocrystalline gypsum mixed with calcite (b) 
each of the three different zones of the limestone sample, i.e., the two laser-cleaned surfaces and the original encrusted surface. The DP LIBS spectra were acquired in the collinear geometry configuration using two laser beams of $45 \mathrm{~mJ}$ energy focused and aligned to hit the sample in the overlapping mode. The temporal parameters used in the experiment were optimized for the best LIBS signal, i.e., the delay time was $500 \mathrm{~ns}$, the gate time $1 \mu \mathrm{s}$ and the interpulse delay $500 \mathrm{~ns}$.

In order to characterize the encrustation/limestone interface and the texture of the sample, a thin polished petrographic section of the sample was prepared and examined by polarized optical microscopy (OM) using a ZEISS Axioskop microscope equipped with a digital camera. Further, analyses by SEM-EDS were performed using a JEOL (JSM-6510, Thermo Scientific) instrument equipped with an EDAX microanalysis component operating in the secondary electron mode at an accelerating voltage of $15 \mathrm{kV}$, a beam current of $0.2 \mathrm{nA}$, an acquisition time of $100 \mathrm{~s}$ and a dead time of $30 \%$.

\section{Results and discussion}

\section{Optical and scanning electron microscopy analyses}

Before performing the cleaning process, a preliminary petrographic, mineralogical and textural analysis was performed to infer the petrographic nature of the sample, the type of degradation and the possible presence of any patina. The OM and SEM results provided information on the micromorphological characteristics of both the substrate and the black crust and on the interactions between the stone and the damaged layer, while SEM-EDS analysis yielded the major elements composition of the crust.

In particular, OM results confirmed that the rock sample is a dedolomitized limestone, i.e., the texture of the original rock was apparently erased by a dedolomitization process (Fig. 2a). The lozenge-shaped dolomite crystals were replaced by pseudomorphic microcrystalline calcite.

Dedolomitization is a natural phenomenon in which calcite replaces dolomite by interaction with groundwater in some specific circumstances (Doehne et al. 1992). As to date, the dedolomitization process can be reproduced at laboratory scale only at a minor extent, the presence of a reasonably thick layer of dedolomitized material would provide evidence that the artifact has been buried for an extended period of time.

The black crust consisted mainly of cryptocrystalline gypsum mixed with calcite combined with quartz silt (Fig. 2b), together with soot and dust deposits. Gypsum crust formation and surface alteration generally occur in the presence of particulate (dust) deposition, especially in areas sheltered from rain and rain-wash (Cultrone et al. 2004). In particular, black crusts sampled from carbonate stone monuments subject to local urban atmosphere in the Bari area contain an average of $76 \%$ calcium sulfate dehydrated, $2 \%$ carbon from carbonates, $2.5 \%$ carbon other than carbonates (soot) and 19\% other components among which silica (mainly quartz) and aluminosilicates are very abundant (Sabbioni 1995).

The SEM of the limestone sample examined showed the collapse of its internal structure and the occurrence of salt crystallization between grains, whereas the EDS spectrum of the black crust confirmed the presence of gypsum, $\mathrm{CaSO}_{4} 2 \mathrm{H}_{2} \mathrm{O}$.

\section{Depth profile analysis}

The ascertained plasma stability with depth, i.e., the occurrence of no changes of its parameters during ablation, ensures that the large differences measured in peak sizes can be related to a true difference in the element content due to limestone diagenesis and/or weathering. However, the relationship between peak size and element content may result not linear due to chemical and/or physical matrix effects (Cremers and Radziemski 2006). Further, LIBS analysis based on multiple shots per location may result in an overall attenuation of the signal due to less photons returning to the spectrometer as the laser impinges deeper into the target and plasma becomes confined within the ablation crater. As a result, the decreasing trend shown by many peaks with depth can be ascribed, not only to a change of composition, but also to an overall lowering of the returned signal (Lanza et al. 2015). To overcome this problem, a new calibration procedure for deep elemental profiling analysis of bronze artifacts was applied by Agresti and Siano (2014), who used a simple model to estimate the ablation rate and derive the depth spatial calibration scale.

Further, to gain the quantitative compositional profiles from the sequence of experimental spectra, the number of laser pulses should be converted into the actual ablation depth, and the atomic emission intensity ratios into elemental concentrations. These procedures should consider also the possible modification of ablation conditions and plasma dynamics related to changes of crater depth and shape. The non-negligible effects on ablation dynamics (Ruf et al. 2001) and consequently on spectral line intensity ratios, as expected in this case with respect to a flat surface, make depth calibration a critical step to achieve reliable quantifications (Corsi et al. 2005; Zeng et al. 2006).

The depth profile analysis of the black crust and cleaned zones was performed using the DP LIBS configuration in collinear mode, which allowed to evaluate the decrease or disappearance in specific elemental components with 

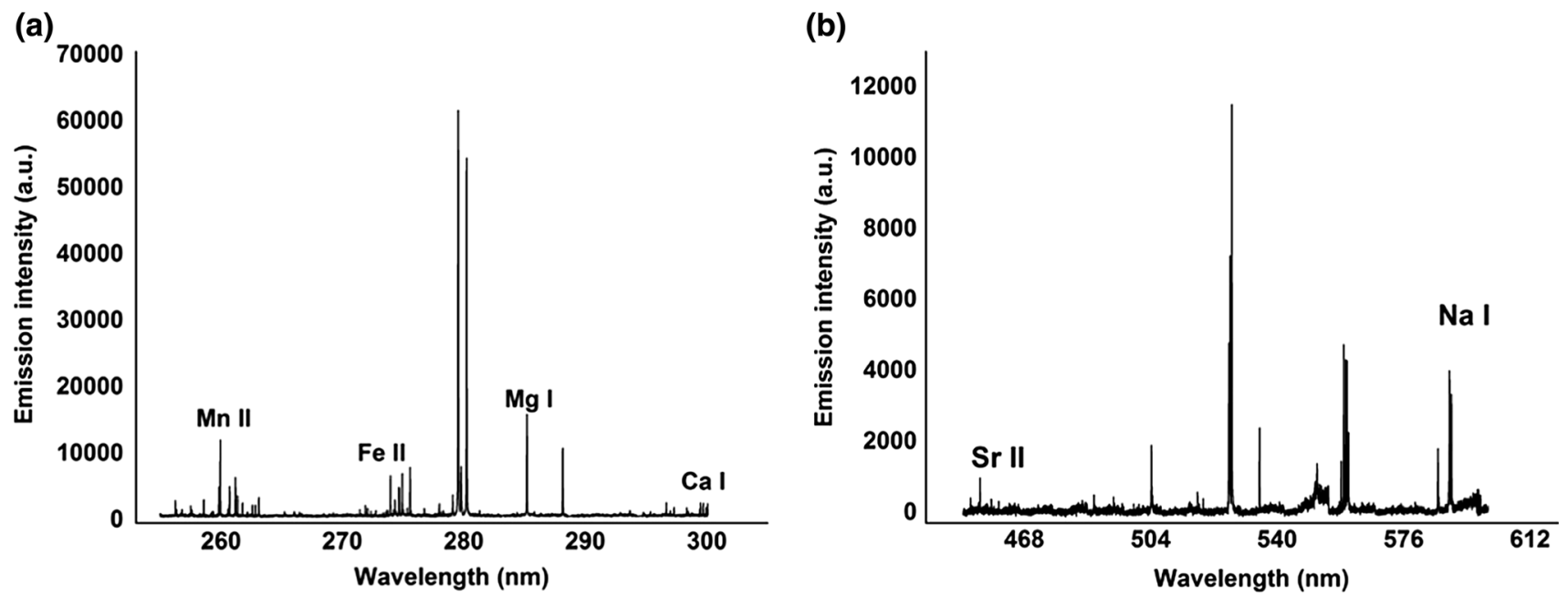

Fig. 3 Typical emission spectrum of the black crust
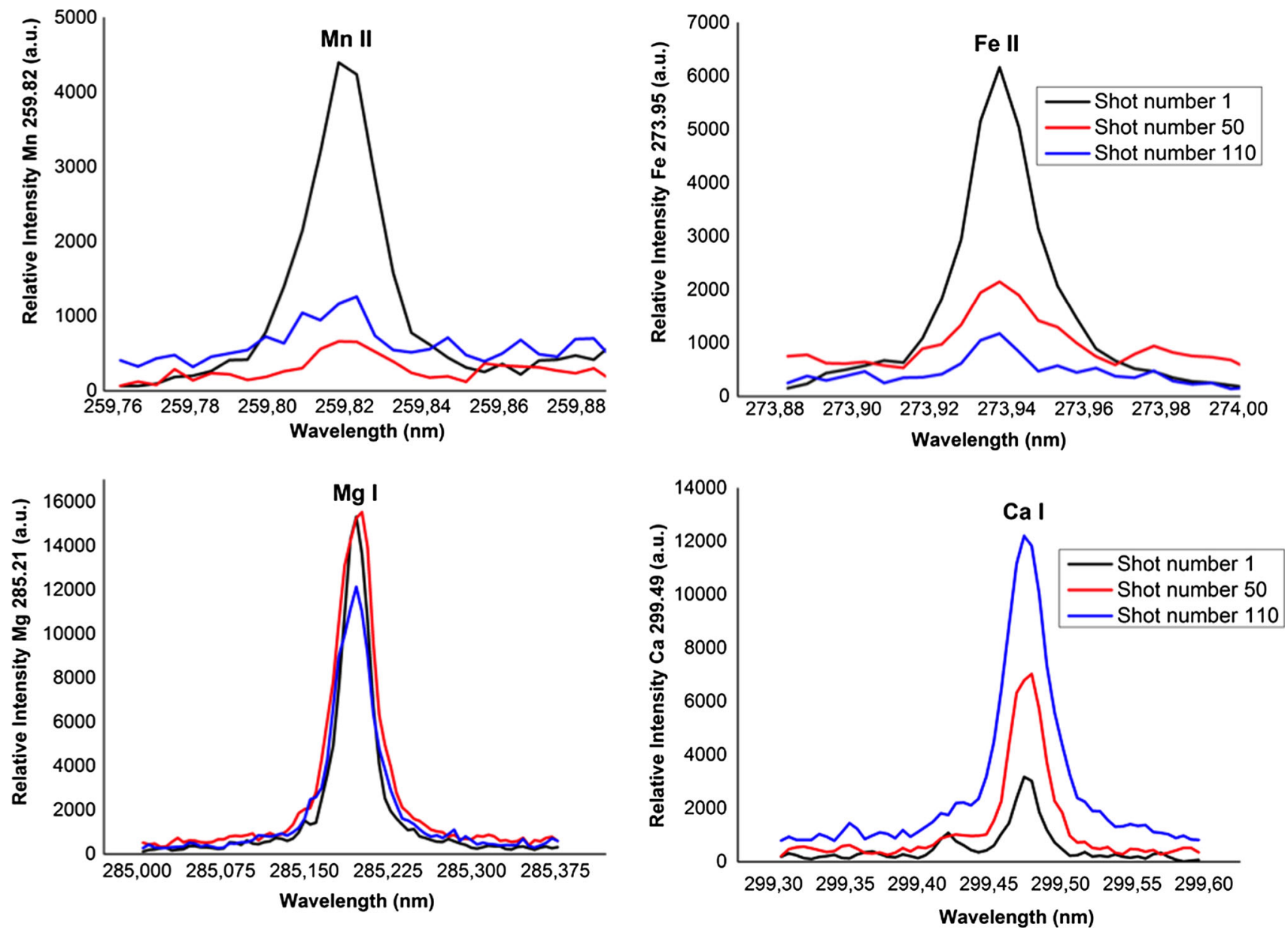

Fig. 4 Mn II, Fe II, Mg I and Ca I peak intensity changes in the black crust zone as a function of laser shot number/crater depth

depth. The estimated crater depth after 110 shots was $\sim 1 \mathrm{~mm}$, i.e., about $9 \mu \mathrm{m}$ per shot. In order to evaluate whether trends observed for emission peaks were actually significant, these were compared, for each location, to the total emission spectra, i.e., to the sum of all counts from the spectrometer at each wavelength prior to normalization. 


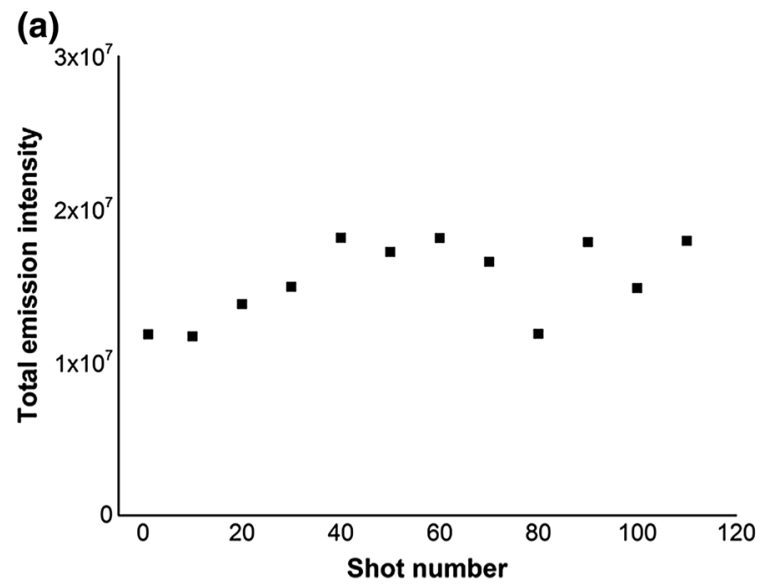

(b)

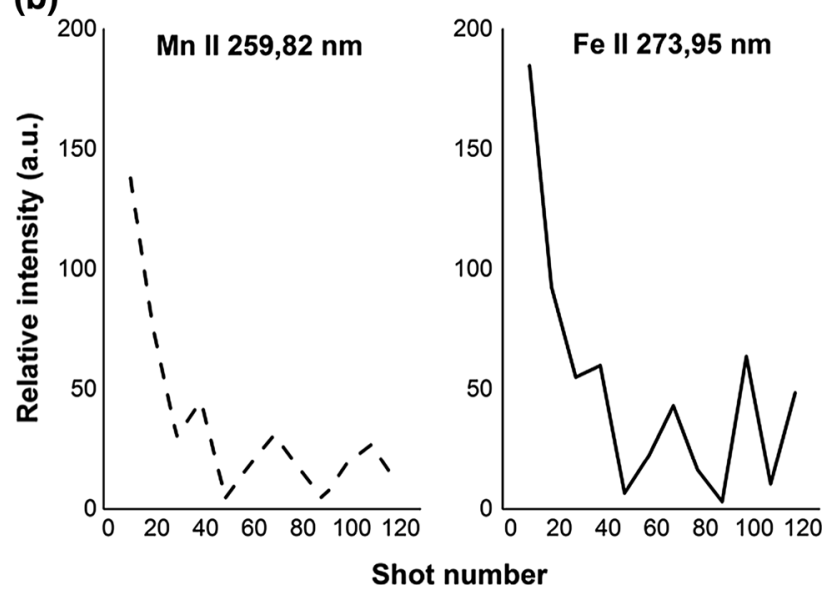

Fig. 5 Total emission intensity (a), and Mn II and Fe II peak relative intensity (b) for the black crust zone as a function of laser shot number/crater depth

Figure 3 shows a typical black crust spectrum acquired after the first two shots in the spectral range from 250 to 300 (Fig. 3a) and 450-612 nm (Fig. 3b), where the peaks selected in this study, i.e., those of Mn II, Fe II, Mg I, Ca I, $\mathrm{Sr}$ II and Na I, are identified. The peak intensity changes of the elements $\mathrm{Mn}, \mathrm{Fe}, \mathrm{Mg}$ and $\mathrm{Ca}$ in the black crust zone as a function of laser shot number, i.e., crater depth, are shown in Fig. 4. In particular, the Mn II and Fe II peaks generally showed a clear intensity decrease with increasing shot numbers, i.e., the crater depth in the three zones examined (Figs. 4, 5, 6). The two peaks featured a higher intensity and a more marked decrease in the black crust zone, whereas in the other two zones the changes were more attenuated by previous laser cleaning (Figs. 4, 5, 6). Actually, the trends observed for the peaks of Mn II at $259.82 \mathrm{~nm}$ and Fe II at 273.95 were significant because the order of magnitude of the total emission spectra of both the black crust and the laser-cleaned zones using the sequence 1064-532 nm was similar for each location, which confirmed that the plasma parameters were not influenced
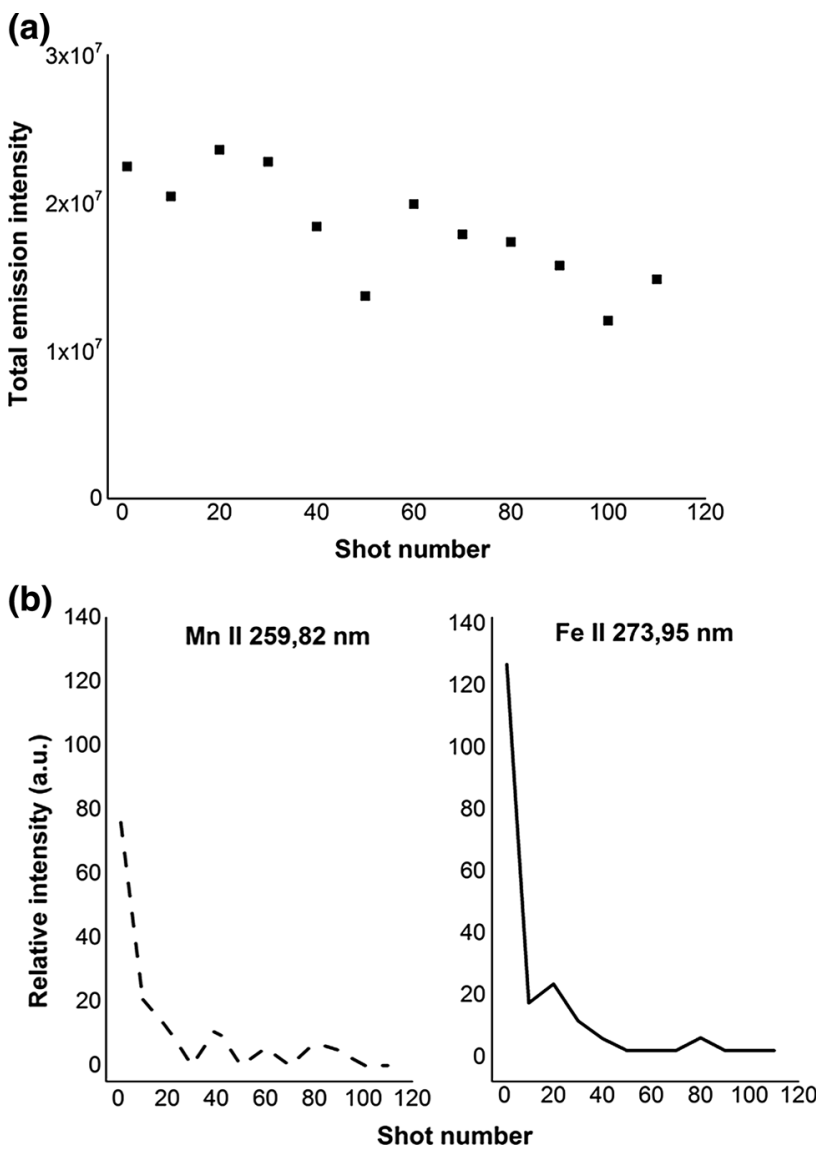

Fig. 6 Total emission intensity (a), and Mn II and Fe II peak relative intensity (b) for the zone laser cleaned by the sequence 1064-532 nm as a function of laser shot number/crater depth

during the in-depth analysis. The presence of $\mathrm{Fe}$ and $\mathrm{Mn}$ in the black crust can be ascribed mainly to atmospheric pollution effects, whereas the high content of $\mathrm{Ca}$ and $\mathrm{Mg}$ in this zone can be related mainly to the composition of the limestone underneath.

An increasing concentration of $\mathrm{Sr}$ with increasing number of laser shots, i.e., crater depth, similar to that of $\mathrm{Ca}$, was measured in the black crust zone (Fig. 7a, b). The $\mathrm{Sr}$ concentration exhibited an approximately increasing trend. Besides Sr present as a site substitute of $\mathrm{Ca}$, the limestone itself may represent another possible source of $\mathrm{Sr}$, as $\mathrm{Sr}$ and other trace elements may concentrate in the hardest parts of aragonite $\left(\mathrm{CaCO}_{3}\right.$ polymorph) originated from marine organisms. The increasing concentration of $\mathrm{Sr}$ with depth might be due to a dedolomitization process of the rock or to a previous diagenesis of aragonite. Further, Sr-rich and Mg-rich sulfates might form and $\mathrm{Sr}$ might originate from atmospheric pollution and/or microbial activity.

The increasing concentration of $\mathrm{Na}$ measured with increasing the number of laser shots, i.e., the crater depth (Fig. 7c, d), could be attributed to the influx of seawater 

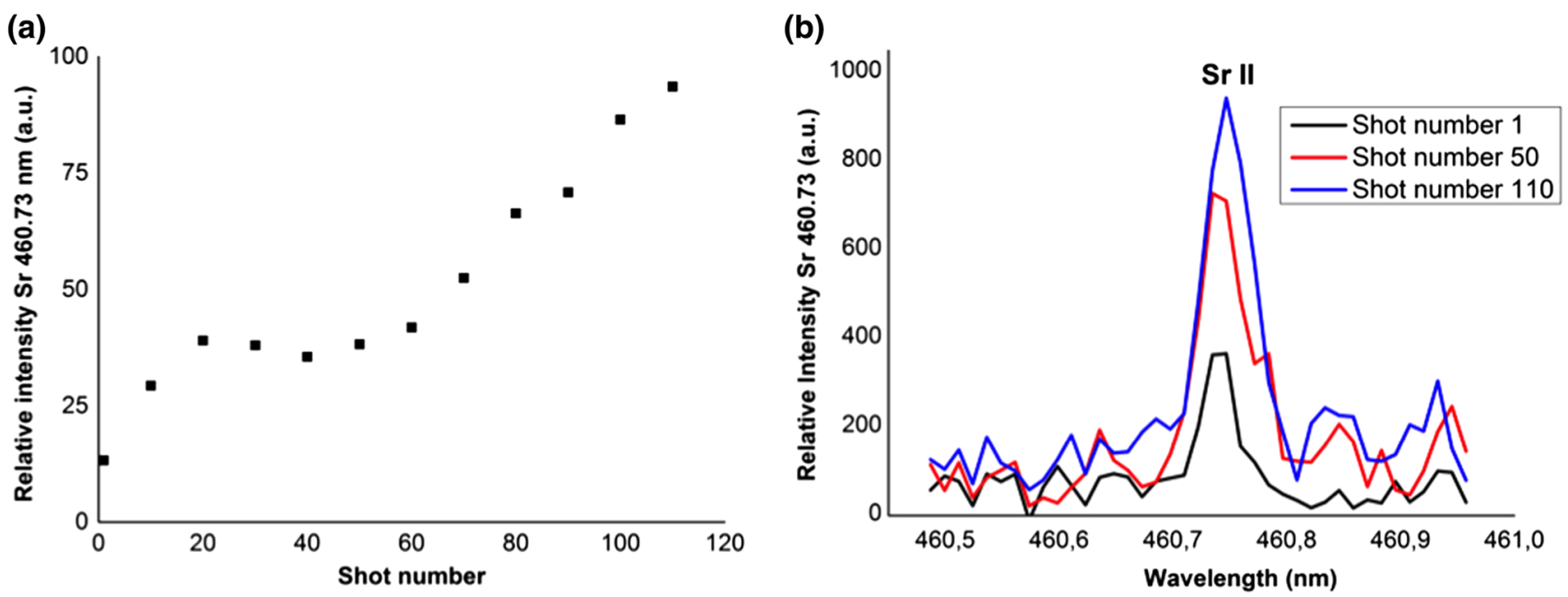

(c)

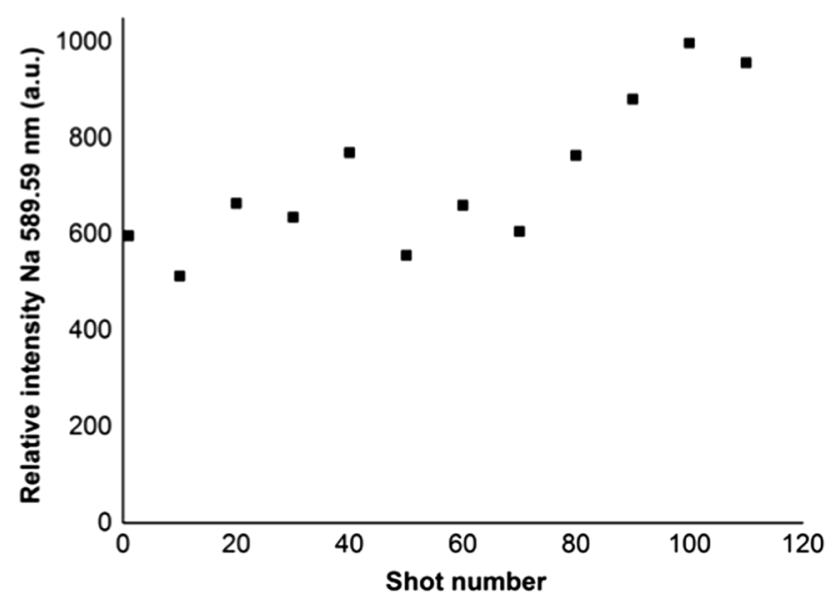

(d)

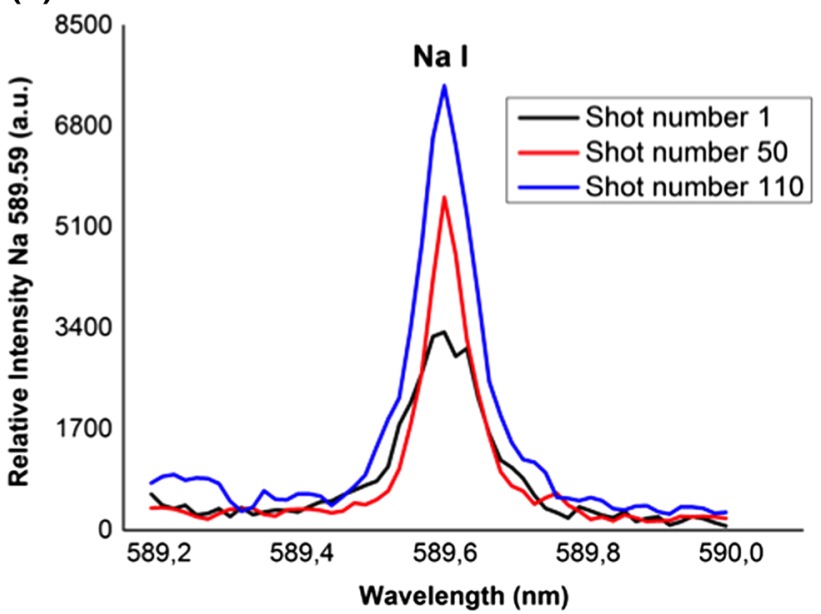

Fig. $7 \mathrm{Sr}$ II $(\mathbf{a}, \mathbf{b})$ and $\mathrm{Na} \mathrm{I}(\mathbf{c}, \mathbf{d})$ peak intensity changes in the black crust zone as a function of laser shot number/crater depth

originated from marine aerosol, due to the proximity of the castle to the shoreline. The abundance of $\mathrm{Na}$ in deeper layers could derive also from migration of soluble salts from the ground through the porous stone network on dependence of textural features. Actually, salt crystallization is one of the most relevant damaging processes that affects the building and decorative elements made of limestones. The internal crystallization of salts usually leads to granular disintegration, crumbling and exfoliation of the stone, which are typical damage effects related to this process. In addition to anthropogenic air pollution, extrinsic sources of ions in precipitated salts also include natural marine aerosols in coastal area.

The marked decrease in $\mathrm{Mg} / \mathrm{Ca}$ ratio with increasing shot number, i.e., crater depth, in the black crust layer down to approximately $200 \mu \mathrm{m}$ which corresponds to about 20 double pulses (Fig. 8a) is difficult to explain. However, after about 20 shots, i.e., after the almost complete removal of the black crust, the $\mathrm{Mg} / \mathrm{Ca}$ ratio remains almost constant in the material underneath (Fig. 8a), and similar to the $\mathrm{Mg} / \mathrm{Ca}$ value measured in the two lasercleaned zones (Fig. 8b). Thus, the depth corresponding to about 20 double pulses would represent the transition from the weathered/altered rock, i.e., the black crust, to the limestone underneath (Fig. 8a, b, circled points).

Minerals can chemically break down at the surface due to interactions with the atmosphere or burial environment. The surface of an ancient rock may include materials that arise partially from the interactions of the rock surface with its environment over a certain period of time. Thus, LIBS depth profile analysis would be able to infer differences in the processes involved in rock transformation when passing from weathering phenomena to geological processes such as diagenesis. In particular, weathering processes involve extended modifications of rock and mineral surfaces, which depend markedly on various exogenic forces, including insolation, frost, water, atmosphere and organisms, whereas the diagenesis comprises all those changes that may occur in a sediment starting from its deposition. 
(a)

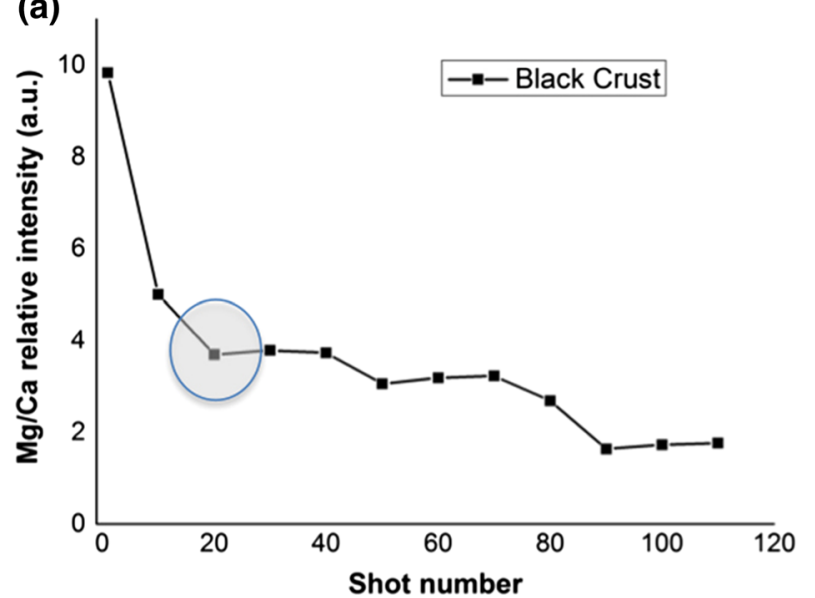

(b)

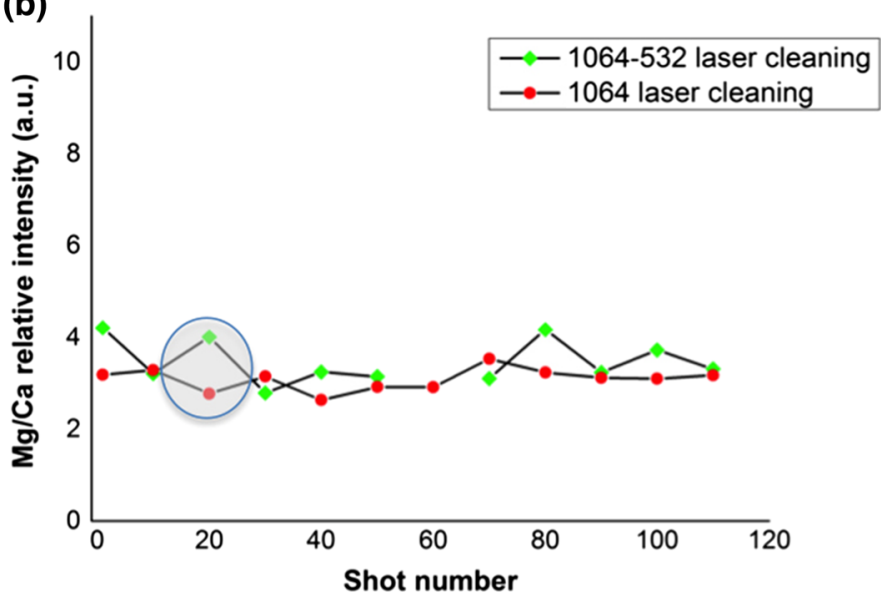

Fig. 8 Ratio of the intensities of atomic LIBS emission lines of $\mathrm{Mg}$ I at $285.21 \mathrm{~nm}$ and $\mathrm{Ca}$ I at $534.95 \mathrm{~nm}$ versus the number of laser pulses/ crater depth in the black crust zone (a), and the two zones cleaned at 1064-532 and at 1064 (b)

\section{Conclusions}

The LIBS technique was confirmed to be a powerful diagnostic technique able to monitor and control the elemental composition of the surface zone of the limestone sample, so supplementing invasive traditional laboratory analyses. Further, LIBS appeared to be a very useful tool for the confirmation of the laser cleaning efficiency in removing the weathered layer from the surface of the limestone sample with minimal damage. The application of DP LIBS configuration stratigraphy was shown to be successful in assessing the decrease or disappearance with depth in specific elemental components that would indicate the borderline between rock diagenesis processes and subsequent weathering processes. In particular, the systematic decrease in $\mathrm{Fe}$ and $\mathrm{Mn}$ peak intensities measured downward the entire sample profile indicated that the content of these elements in the coating layer is higher than in the rock underneath, and can be feasibly ascribed to atmospheric pollution effects. On the contrary, the increase in $\mathrm{Ca}$ and $\mathrm{Sr}$ concentrations with depth indicates the passage from the weathered layer to the limestone underneath. The presence of $\mathrm{Na}$ can be ascribed mainly to external sources as the influx of sea water originated from marine aerosol. Further, the occurrence of no changes of plasma parameters, i.e., plasma stability, during ablation was verified.

As a whole, the results of this study confirm LIBS as a promising technique for studying rock alteration processes due to environmental factors. Further, the presence of weathering layers is considered to be a very good piece of evidence in authentication studies of rock artifacts. However, the application of LIBS in this sector is still in its infancy for the majority of rock types; thus, more extensive research is required to confirm the efficiency and usefulness of this approach.

Acknowledgements The authors kindly acknowledge the financial funding received under the project "Il restauro delle grandi opere in Puglia: l'innovazione attraverso le nanotecnologie e metodologie diagnostiche avanzate," P.O. Puglia FESR 2007-2013, Bando “Aiuti a Sostegno dei Partenariati Regionali per l'Innovazione" (3Z3VZ46) and Embrapa Instrumentation, São Carlos/SP, Brazil.

\section{References}

Agresti J, Siano S (2014) Depth-dependent calibration for quantitative elemental depth profiling of copper alloys using laser-induced plasma spectroscopy. Appl Phys A 117:217-221. doi:10.1007/ s00339-014-8363-x

Anglos D, Detalle V (2014) Cultural heritage applications of LIBS. In: Musazzi S, Perini U (eds) Laser-Induced Breakdown Spectroscopy, vol 182. Springer Series in Optical Sciences. Springer, Berlin, pp 531-554

Beck K, Al-Mukhtar M (2010) Weathering effects in an urban environment: a case study of tuffeau. In: Smith BJ, Gomez-Heras M, Viles HA, Cassar J (eds) Limestone in the built environment: present-day challenges for the preservation of the past. Geological Society, Special Publications, London, pp 103-111

Corsi M, Cristoforetti G, Hidalgo M et al (2005) Effect of laserinduced crater depth in laser-induced breakdown spectroscopy emission features. Appl Spectrosc 59:853-860

Cremers DA, Radziemski LJ (2006) Handbook of laser-induced breakdown spectroscopy. Wiley, New York

Cultrone G, Rodriguez-Navarro C, Sebastian E (2004) Limestone and brick decay in simulated polluted atmosphere: the role of particulate matter. In: Saiz-Jimenez C (ed) Air Pollution and Cultural Heritage. Balkema Publishers, Leiden, pp 141-145

Dell'Anna L, Laviano R (1990) Cretaceous limestone in historic buildings and monuments of Apulia (Southern Italy). Geochemical and mineralogical characteristics and decay. Plinius 2:51-53

Doehne E, Podany J, Showers W (1992) Analysis of weathered dolomitic marble from Thasos, Greece. In: Waelkens M, Herz N, Moens L (eds) Ancient stones: quarrying, trade and provenance. Interdisciplinary studies on stones and stone technology in 
Europe and near East from the prehistoric to the early Christian period. Acta Archaeologica Lovaniensia, Monographiae 4. Leuven University Press, Leuven, pp 243-246

Figueiredo C, Folha R, Mauricio A, Alves C, Aires-Barros L (2010) Pore structure and durability of Portuguese limestones: a case study. In: Smith BJ, Gomez-Heras M, Viles HA, Cassar J (eds) Limestone in the built environment: present-day challenges for the preservation of the past. Geological Society, Special Publications, London, pp 157-170

Kiros A, Lazic V, Gigante GE, Gholap AV (2013) Analysis of rock samples collected from rock hewn churches of Lalibela, Ethiopia using laser-induced breakdown spectroscopy. J Archaeol Sci 40:2570-2578

Lanza NL, Ollila AM, Cousin A et al (2015) Understanding the signature of rock coatings in laser-induced breakdown spectroscopy data. Icarus 249:62-73

Maravelaki-Kalaitzaki P, Anglos D, Kilikoglou V, Zafiropulos V (2001) Compositional characterization of encrustation on marble with laser induced breakdown spectroscopy. Spectrochim Acta Part B 56:887-903

Miziolek AW, Palleschi V, Schecter I (2006) Laser induced breakdown spectroscopy (LIBS): fundamentals and applications. Cambridge University Press, Cambridge

Noll R (2012) Laser induced breakdown spectroscopy (LIBS): fundamentals and applications. Springer, Berlin

Osticioli I, Agresti J, Fornacelli C, Turbanti Memmi I, Siano S (2012) Potential role of LIPS elemental depth profiling in authentication studies of unglazed earthenware artifacts. J Anal At Spectrom 27:827-833

Ruf A, Berger P, Dausinger F, Hügel H (2001) Analytical investigations on geometrical influences on laser drilling. J Phys D Appl Phys 34:2918-2925
Sabbioni C (1995) Contribution of atmospheric deposition to the formation of damage layers. Sci Total Environ 167:49-55

Senesi GS (2014) Laser-induced breakdown spectroscopy (LIBS) applied to terrestrial and extraterrestrial analogue geomaterials with emphasis to minerals and rocks. Earth Sci Rev 139:231-267

Senesi GS, Carrara I, Nicolodelli G, Milori DMBP, De Pascale O (2016) Laser cleaning and laser-induced breakdown spectroscopy applied in removing and characterizing black crusts from limestones of Castello Svevo, Bari, Italy: a case study. Microchem J 124:296-305

Siano S, Bartoli L, Mencaglia AA, Miccio M, Agresti J (2009) Use of neutron diffraction and laser-induced plasma spectroscopy in integrated authentication methodologies of copper alloy artefacts. Il Nuovo Cimento 124 B:671-686

Siano S, Cacciari I, Mencaglia AA, Agresti J (2011) Spatially calibrated elemental depth profiling using LIPS and 3D digital microscopy. Eur Phys J Plus 126:120. doi:10.1140/epjp/i201111120-y

Siano S, Agresti J, Cacciari I, Ciofini D, Mascalchi M, Osticioli I, Mencaglia AA (2012) Laser cleaning in conservation of stone, metal, and painted artifacts: state of the art and new insights on the use of the Nd:YAG lasers. Appl Phys A 106:419-446. doi:10.1007/s00339-011-6690-8

Smith BJ, Gomez-Heras M, Viles HA (2010) Underlying issues on the selection, use and conservation of building limestone. In: Smith BJ, Gomez-Heras M, Viles HA, Cassar J (eds) Limestone in the built environment: present-day challenges for the preservation of the past. Geological Society, Special Publications, London, pp 1-11

Zeng X, Mao X, Mao S, Wen SB, Greif R, Russo RE (2006) Laserinduced shockwave propagation from ablation in a cavity. Appl Phys Lett 88:061502 